\title{
Indução de resistência em plantas de berinjela por Lentinula edodes e Agaricus blazei contra Ralstonia solanacearum: aspectos bioquímicos e biomassa vegetal
}

\author{
Ricardo Ferrari Silva' ${ }^{1}$, Sérgio Florentino Pascholati², Ivan Paulo B edendo²
}

Departamento de Entomologia, Fitopatologia e Zoologia A grícola, ESALQ/USP, CP 09, CEP 13418-900, Piracicaba, SP; e-mail: ipbedend@esalq.usp.br ${ }^{1}$ B olsista CAPES. ${ }^{2}$ B olsistas CN Pq. Parte da Tese de Doutorado do primeiro autor.

A utor para correspondência: Sérgio F. Pascholati

Data de chegada: 09/02/2007. A ceito para publicação em: 16/01/2008

1447

\section{RESUMO}

Silva, R .F.; Pascholati, S.F.; B edendo, I.P. Indução de resistência em plantas de berinjela por L entinula edodes e Agaricus blazei contra Ralstonia solanacearum: aspectos bioquímicos e biomassa vegetal. Summa Phytopathologica, v.34, n.2, p.137-144, 2008

A murcha bacteriana, causada por Ralstonia solanacearum, é considerada uma doença de importância para a cultura da berinjela, sendo de difícil controle. 0 controle de doenças através de indução de resistência é um método que vêm se revelando como promissor. Basidiomas de Agaricus blazei e Lentinula edodes possuem substâncias do tipo antibiótico e outras substâncias capazes de atuarem como elicitoras da resposta de resistência em plantas, mostrando-se assim promissores no controle alternativo de fitopatógenos. 0 presente trabalho foi conduzido com o objetivo de estudar o efeito de extratos aquosos dos fungos e do indutor químico acibenzolar-S-metil (aSm) sobre o crescimento da bactéria in vitro e o controle da murcha bacteriana, bem como investigar seu ef eito sobre a atividade de determinadas enzimas da planta. 0 efeito inibitório sobre o patógeno foi avaliado usando diferentes concentrações dos extratos aquosos. A indução de resistência foi estudada em plantas tratadas com 0 indutor biológico e químico, medindo-se a intensidade de murcha e determinando-se as alterações de algumas enzimas. Os resultados revelaram que os isolados de A. blazei e L. edodes, utilizados em diversas diluições, não exerceram efeito inibitório in vitro. Em relação à indução de resistência, extratos dos isolados A bl-11 e A bl-28 de A. blazei $(15 \%, v / v)$ e 0 aSm $(0,05 \mathrm{~g} / \mathrm{L})$ promoveram redução significativa na ocorrência de folhas murchas, quando aplicados dois dias antes da inoculação. 0 aumento na atividade de peroxidase foi verificado em plantas tratadas com extratos de A bl-11, A bl-28 e com suspensão de aSm. A atividade de quitinase, fenilalanina amônia-liase e polifenoloxidase não foi alterada nas plantas tratadas com extrato de A bl-28 e com o aSm. No entanto, plantas de berinjela tratadas com A bl-11 exibiram uma aumento na atividade de fenilalaniana amônialiase e de polifenoloxidase, enquanto que a atividade de quitinase não foi alterada. Com base nos resultados, ficou evidenciado que $0 \mathrm{aSm}$ e os isolados Abl-11 e A bl-28 de A. blazei apresentam potencial para induzir resistência em berinjela contra R. solanacearum.

Palavras-chave adicionais: murcha bacteriana, proteínas- $\mathrm{R}$, indutores bióticos.

\section{ABSTRACT}

Silva, R.F.; Pascholati, S.F.; B edendo, I.P. Induction of resistance in eggplants by Lentinula edodes and Agaricus blazei against Ralstonia solanacearum: biochemical aspects and vegetable biomass. Summa Phytopathologica, v.34, n.2, p.137-144, 2008

The bacterial wilt, caused by Ralstonia solanacearum, is an important disease for eggplants, which control is difficult. Induction of resistance in plants is a promising method for disease control. Fruiting bodies of Agaricus blazei and Lentinula edodes have substances that exhibit antibiotic activity or are able of acting as elicitors of resistance in plants. The objectives of the present work were to verify the effect of aqueous extracts from the mushrooms and the plant activator acibenzolar-S-methyl (aSm) on in vitro bacterial growth and to control bacterial wilt as well as to investigate the activity of certain enzymes. The inhibitory effect on the pathogen was evaluated by using different concentrations of aqueous extracts. The induced resistance was studied in plants treated with the biological or chemical inducers, by measuring the intensity of wilt and alterations in some defense-related enzymes. The results showed that the isolates of $A$. blazei and $L$. edodes, used in several dilutions, did not inhibit in vitro bacterial growth. The extracts of the isolates Abl-11 and A bl-28 from A. blazei $(15 \%, v / v)$ and aSm $(0,05 \mathrm{~g} / \mathrm{L})$ caused significant reduction in the occurrence of wilted leaves, when applied two days before inoculation. Plants treated with aSm or aqueous extracts of Abl-11 and Abl-28 exhibited increased peroxidase activity. The chitinase, phenylalanine ammonia-lyase and polyphenoloxidase activities did not change in plants treated with $\mathrm{Abl}-28$ and $\mathrm{aSm}$. However, plants treated with Abl-11 exhibited increased phenylalanine ammonia-lyase and polyphenoloxidase activities, while the chitinase activity was not affected. Based upon the results, it was shown that the aSm and the isolates A bl-11 and Abl-28 of A. blazei exhibited a potential to induce resistance in eggplants against $R$. solanacearum.

Additional keywords: bacterial wilt, PR-protein, biotic inducers 
Entre as diversas doenças que atacam as solanáceas, a murcha bacteriana, causada por Ralstonia solanacearum (Smith) é considerada a principal doença vascular de etiologia bacteriana encontrada no mundo, especialmente nas regiões tropicais e subtropicais, onde infecta plantas pertencentes a mais de 50 famílias botânicas $(12,16)$. Como o controle da bactéria, em condições favoráveis, é difícil, medidas como rotação de cultura com gramíneas (milho, arroz, sorgo, cana-de-açúcar e pastagens), plantio em áreas onde não há histórico da doença, isolamento dos focos iniciais da doença e cuidados com a irrigação se tornam necessárias (15). Com relação ao controle químico da murcha bacteriana, este tem apresentado pouco sucesso $(16,28)$.

No contexto da proteção de plantas, a resistência induzida pode ser visualizada como uma das medidas de controle alternativo. A indução de resistência em plantas vem sendo estudada desde o início do século XX (2). Porém, apenas recentemente, a potencialidade de seu emprego no controle de enfermidades tem recebido o merecido destaque $(5,10,21)$. Ela tem sido demonstrada em diversas espécies de plantas, ocorrendo em resposta ao tratamento, por exemplo, com fungos, bactérias e elicitores microbianos ou químicos $(11,24)$.

A resistência induzida é caracterizada pela ativação de mecanismos bioquímicos, que podem envolver a síntese e atividade de peroxidase, ß-1,3-glucanase, quitinase, fenilalanina amônia-liase e polifenoloxidase (4). Dentre os elicitores químicos ou abióticos, destaca-se o acibenzolarS-metil (aSm), um derivado benzotiadiazólico, capaz de atuar como análogo funcional do ácido salicílico, o qual possibilita proteção de campo contra um amplo espectro de doenças em diversas espécies cultivadas $(10,17)$. Entre os diversos agentes bióticos conhecidos, os cogumelos Lentinula edodes e Agaricus blazei têm sido pesquisados como potenciais agentes indutores de resistência para o controle de doenças em plantas (9). D entre as substâncias presentes no basidioma e no micélio de L. edodes e de A. blazei, a lentinana, uma glucana obtida a partir de L. edodes, protegeu plantas de maracujá contra $X$ anthomonas campestris pv. passiflorae sem apresentar ef eito direto sobre a bactéria, indicando que a proteção provavelmente ocorreu através da indução de resistência (25).

$A$ atividade antibacteriana de $L$. edodes foi estudada in vitro por I shikawa (13), através da técnica de difusão em sobrecamada de agar semi-sólido. Os 35 isolados de L. edodes testados mostraram atividade contra diversas espécies de bactérias nocivas ao homem ou patogênicas às plantas, sendo que poucas Gram-negativas e diversas Grampositivas tiveram seu crescimento inibido.

Di Piero \& Pascholati (7) verificaram que o extrato aquoso de um isolado de A. blazei reduziu significativamente a severidade da mancha bacteriana em tomateiro, em casa-de-vegetação, obtendo-se uma proteção média de $45 \%$, quando o extrato foi aplicado 5 dias antes da inoculação com o patógeno. Observou-se também um aumento na atividade de $\square$-1,3-glucanase, sugerindo assim a indução de resistência em tomateiro contra $X$ anthomonas vesicatoria.

D essa forma, o presente trabal ho teve por objetivos avaliar a ação dos extratos aquosos de L. edodes e de A. blazei como indutores de resi stência em plantas de berinjela contra a bactéria causadora da murcha e investigar o seu efeito sobre a atividade das enzimas peroxidase, quitinase, fenilalanina amônia-liase e polifenoloxidase.

\section{MATERIAL E MÉTODOS}

O btenção dos extratos aquosos de L. edodes e A. blazei

Os cogumelos foram produzidos no Departamento de Produção Vegetal (M ódulo de Cogumelos), da Faculdade de Ciências $A$ gronômicas - UNESP/Botucatu, sendo enviados pela Profa Dra. M arli T. A.
M inhoni. Para obtenção dos extratos aquosos dos isolados L e-96/22 e Le-96/17 de L. edodes e A bl-11 e A bl-28 de A. blazei, cada grama de pó seco obtido de basidiomas desidratados e moídos foi dissolvida em $14 \mathrm{~mL}$ de água destilada. A pós $24 \mathrm{~h}$ de incubação a $4{ }^{\circ} \mathrm{C}$, a suspensão foi filtrada em papel de filtro comum e centrifugada a $20.000 \mathrm{~g}$ por 25 min. Para os bioensai os realizados em casa-de-vegetação, os extratos brutos foram diluídos a $5 \%, 10 \%, 15 \%$ e $20 \%$ (v/v). Para os testes realizados in vitro, os extratos aquosos foram filtrados em membrana tipo Millipore $(0,2 \mu \mathrm{m})$, sob condições assépticas, sendo posteriormente armazenados em geladeira até serem usados.

O btenção e manutenção dos fitopatógenos e das plantas

U tilizou-se o isolado R s84 de R. solanacearum, cedido pel o Centro $\mathrm{N}$ acional de Pesquisa de Hortaliças da E mbrapa. Para a realização dos ensaios, o isolado foi cultivado no meio de tetrazólio (14) e incubado por $48 \mathrm{~h}$ a $28 \pm 2^{\circ} \mathrm{C}$. 0 isolado bacteriano foi preservado em tubos de ensaio contendo o meio nutriente-agar (NA) coberto por óleo mineral esterilizado e em água destilada esterilizada (30), em temperatura ambiente ou na geladeira. Em todos os bioensaios, foi utilizado o híbrido de berinjela Hib. F 1 N apolitana, cedido pela empresa Sakata Seed Sudamerica $L$ tda. A s plantas foram produzidas em bandejas de poliestireno de 128 células, contendo o substrato agrícola Plantmax ${ }^{\circledR}$ (Eucatex) e mantidas sob condições de casa-de-vegetação.

\section{Efeito in vitro dos cogumelos sobre R. solanacearum}

Tubos de ensaio contendo $7 \mathrm{~mL}$ de água destilada esterilizada receberam extratos aquosos dos isolados de L. edodes e A. blazei, obtendo-se concentrações finais de $5 \%, 10 \%, 15 \%$ e $20 \%$ (v/v). 0 tratamento controle foi representado por tubos contendo somente água. Posteriormente, adicionou-se $1 \mathrm{~mL}$ de suspensão bacteriana em cada tubo, de modo que a concentração final fosse de $10^{8} \mathrm{ufc} / \mathrm{mL}$. 0 ensaio foi realizado com cinco repetições por tratamento, onde cada tubo representou uma repetição. Os tubos foram mantidos no escuro a $28 \pm 2{ }^{\circ} \mathrm{C}$ por $24 \mathrm{~h}$. A líquotas de $300 \mu \mathrm{L}$ de cada tubo foram pipetadas em placas de Petri contendo o meio nutriente-agar (NA) e espal hadas com 0 auxílio de uma alça de D rigalsky. A s placas foram novamente mantidas no escuro a $28 \pm 2{ }^{\circ} \mathrm{C}$, por $48 \mathrm{~h}$. Para aval iação, $20 \mathrm{~mL}$ de água destilada foram adicionados a cada placa e a leitura da absorbância foi feita em espectrofotômetro (550 nm). Este ensaio foi realizado em duplicata.

Proteção de plantas de berinjela em casa-de-vegetação

Os extratos aquosos dos cogumelos, a solução de acibenzolar-smetil $\left(0,05 \mathrm{~g} / \mathrm{L}\right.$; Bion ${ }^{\circledR}$, Syngenta) e água foram aspergidos sobre as plantas até 0 ponto de escorrimento e, após dois dias, a bactéria foi inoculada. 0 método de inoculação consistiu de ferimento no caule através da introdução de um alfinete entomológico número 3, que transpassou uma gota de $10 \mu \mathrm{l}$ da suspensão bacteriana de $10^{8} \mathrm{ufc} / \mathrm{mL}$ (equival ente a absorbância de 0,1 a $550 \mathrm{~nm}$ ), que estava depositada na axila foliar (19). Foram real izadas 10 repetições/tratamento, onde cada planta representou uma repetição. 0 delineamento experimental foi do tipo compl etamente casualizado. As aval iações foram feitas no $50 \mathrm{e}$ 10 ㅇa após a inoculação, com base na porcentagem de folhas murchas e nos pesos das massas fresca e seca das plantas. Os tratamentos conduzidos estão apresentados na Tabela 1. Este ensaio foi realizado em duplicata.

E feito de extratos fúngicos sobre a atividade de enzimas

A s amostras consistiram de todas as fol has de cada planta coletadas aos $0,1,2,3,4,7$ e 12 dias após os tratamentos (Tabela 2). Em cada 
Tabela 1. Tratamentos com acibenzolar-S-metil (aSm) e com os isolados dos cogumelos Agaricus blazei (A bl-11 e A bl-28) e Lentinula edodes (Le96/17 e Le-96/22), utilizados no experimento em casa-de-vegetação. As plantas de berinjela foram inoculadas com R. solanacearum (R s84) dois dias depois de tratadas.

\begin{tabular}{|c|c|c|c|}
\hline Tratamento & A gente aplicado & Concentração & Inoculação \\
\hline T 1 & Água & - & Água \\
\hline T 2 & Água & - & Rs84 \\
\hline T 3 & Abl-11 & $5 \%(\mathrm{v} / \mathrm{v})$ & Rs84 \\
\hline T 4 & A bl-11 & $10 \%(\mathrm{v} / \mathrm{v})$ & Rs84 \\
\hline T 5 & Abl-11 & $15 \%(v / v)$ & Rs84 \\
\hline T 6 & A bl-11 & $20 \%(v / v)$ & Rs84 \\
\hline T 7 & Le-96/17 & $5 \%(v / v)$ & Rs84 \\
\hline T 8 & Le-96/17 & $10 \%(\mathrm{v} / \mathrm{v})$ & Rs84 \\
\hline T 9 & Le-96/17 & $15 \%(v / v)$ & Rs84 \\
\hline T 10 & Le-96/17 & $20 \%(v / v)$ & Rs84 \\
\hline T 11 & Le-96/22 & $5 \%(v / v)$ & Rs84 \\
\hline Т 12 & Le-96/22 & $10 \%(\mathrm{v} / \mathrm{v})$ & Rs84 \\
\hline T13 & Le-96/22 & $15 \%(v / v)$ & Rs84 \\
\hline T 14 & Le-96/22 & $20 \%(v / v)$ & Rs84 \\
\hline T 15 & A bl-28 & $5 \%(v / v)$ & Rs84 \\
\hline T 16 & A bl-28 & $10 \%(\mathrm{v} / \mathrm{v})$ & Rs84 \\
\hline T 17 & A bl-28 & $15 \%(v / v)$ & Rs84 \\
\hline Т 18 & A bl-28 & $20 \%(v / v)$ & Rs84 \\
\hline T 19 & aSm & $0,05 \mathrm{~g} / \mathrm{L}$ & Rs84 \\
\hline
\end{tabular}

Tabela 2. Tratamentos com acibenzolar-S-metil (aSm) e com os isolados do cogumelo Agaricus blazei ( $\mathrm{Abl}-11$ e A bl-28), utilizados no experimento em casa-de-vegetação, envolvendo a atividade de enzimas. As plantas de berinjela foram inoculadas com R. solanacearum (Rs84) dois dias depois de tratadas.

\begin{tabular}{|c|c|c|c|}
\hline Tratamento & A gente aplicado & Concentração & Inoculação \\
\hline T 1 & Água & - & Água \\
\hline T 2 & Água & - & Rs84 \\
\hline T 3 & aSm & $0,05 \mathrm{~g} / \mathrm{L}$ & Água \\
\hline T 4 & $\mathrm{aSm}$ & $0,05 \mathrm{~g} / \mathrm{L}$ & Rs84 \\
\hline T 5 & A bl-28 & $15 \%(v / v)$ & Água \\
\hline T 6 & A bl-28 & $15 \%(v / v)$ & Rs84 \\
\hline T 7 & Abl-11 & $15 \%(v / v)$ & Água \\
\hline T 8 & A bl-11 & $15 \%(\mathrm{v} / \mathrm{v})$ & Rs84 \\
\hline
\end{tabular}

tratamento foram utilizadas quatro repetições, onde cada planta representou uma repetição. A s amostras col etadas foram maceradas e homogeneizadas em $4 \mathrm{~mL}$ de tampão de acetato de sódio $100 \mathrm{mM}(\mathrm{pH}$ 5,0 ) e centrifugadas a $20000 \mathrm{~g} / 25 \mathrm{~min}$ a $4^{\circ} \mathrm{C}$. Os sobrenadantes foram coletados e armazenados em congelador a - $20^{\circ} \mathrm{C}$, para avaliação do teor de proteínas totais e atividade enzimática.

Peroxidase (E.C. 1.11.1.7.) - a atividade foi determinada por método espectrofotométrico direto, através da medi da da conversão do guaiacol em tetraguaiacol a $470 \mathrm{~nm}$ (18). A reação foi realizada com $0,1 \mathrm{~mL}$ do extrato proteico misturado com 2,9 mL de uma solução com $250 \mathrm{~mL}$ de guaiacol e $306 \mathrm{~mL}$ de peróxido de hidrogênio em $100 \mathrm{~mL}$ de tampão fosfato $0,01 \mathrm{M}(\mathrm{pH} 6,0)$. Como referência, utilizou-se uma cubeta com $3 \mathrm{~mL}$ da solução contendo guaiacol e peróxido de hidrogênio em tampão fosfato. A atividade da peroxidase foi expressa em unidades de absorbância / min / mg proteína (U .A ./ min / mg prot).

Quitinase (E.C. 3.2.1.14) - para avaliar a atividade utilizou-se a metodologia descrita por Wirth \& Wolf (31), na qual ocorre a liberação de fragmentos solúveis de quitina carboximetilada marcada com remazol brilhante violeta (CM -Chitin-RBV). Foram utilizados $200 \mu \mathrm{L}$ do extrato proteico misturados com $600 \mu \mathrm{L}$ de tampão de extração (acetato de sódio $10 \mathrm{mM}$, pH 5,0) e $200 \mu \mathrm{L}$ do substrato CM -Chitin-RBV $\left(2,0 \mathrm{mg} \cdot \mathrm{mL}^{-1}\right)$. Estas amostras foram incubadas a $40^{\circ} \mathrm{C}$ em banhomaria por $20 \mathrm{~min}$, paralisando-se a reação com a adição de $200 \mu \mathrm{L}$ de $\mathrm{HCl} 1,0 \mathrm{M}$. Em seguida, as amostras foram centrifugadas a $4^{\circ} \mathrm{C}$ por 10 min a $5000 \mathrm{~g}$, procedendo-se então a leitura do sobrenadante em absorbância de $550 \mathrm{~nm}$, utilizando-se uma cubeta de referência com $800 \mu \mathrm{L}$ de tampão de extração $+200 \mu \mathrm{L}$ do substrato CM -ChitinRBV $+200 \mu \mathrm{L}$ de $\mathrm{HCl} 1,0 \mathrm{M}$. Os resultados foram expressos em unidades de absorbância/ $\mathrm{min} / \mathrm{mg}$ de proteína (U.A ./ $\mathrm{min} / \mathrm{mg}$ prot).

Polifenoloxidase (E.C. 1.10.3.1) - a atividade foi determinada de acordo com Duangmal \& A penten (8), pela mensuração da conversão do catecol em quinona. 0 substrato utilizado foi composto por catecol $20 \mathrm{mM}$ dissolvido em tampão fosfato de sódio $100 \mathrm{mM}$ (pH 6,8). Para a reação, que ocorreu a $30^{\circ} \mathrm{C}, 900 \mu \mathrm{L}$ do substrato foram misturados com $100 \mu \mathrm{L}$ do extrato proteico. A s leituras foram efetuadas a cada 10 $\mathrm{s}$ a $420 \mathrm{~nm}$ em espectrofotômetro, durante $1 \mathrm{~min} .0$ diferencial entre a terceira ea quinta leitura foi utilizado para determinação da atividade. 0 s resultados foram expressos em unidades de PPO, sendo que uma unidade foi definida como um incremento de absorbância de 0,001 por min de reação por mg de proteína total.

Fenilalanina amônia-liase (E.C. 4.3.1.5) - a atividade foi determinada pela quantificação colorimétrica do ácido trans-cinâmico liberado do substrato fenilalanina (29). A reação continha $100 \mathrm{ml}$ do extrato proteico misturado com $400 \mathrm{~mL}$ do tampão Tris HCl $25 \mathrm{mM}$ (pH 8,8) e com $500 \mathrm{ml}$ de L-fenilalanina ( $50 \mathrm{mM}$ em tampão Tris $\mathrm{HCl}$ $25 \mathrm{mM}$, pH 8,8), a qual foi incubada por $2 \mathrm{~h}$ a $40^{\circ} \mathrm{C}$. A absorbância das amostras foi determinada a $290 \mathrm{~nm}$, contra tampão de extração, sendo subtraído de cada amostra o valor do controle $(100 \mathrm{~mL}$ do extrato proteico + $900 \mathrm{~mL}$ de tampão Tris $\mathrm{HCl} 25 \mathrm{mM}, \mathrm{pH} 8,8$ ). A atividade enzimática foi expressa em $\mathrm{mg}$ de ácido trans-cinâmico/ min / mg de proteína, utilizando-se uma curva padrão para o ácido.

\section{RESULTADOS E DISCUSSÃO}

Efeito in vitro dos cogumelos sobre $R$ alstonia solanacearum

0 aSm e os isolados de L. edodes e de A. blazei utilizados nos testes in vitro não inibiram o crescimento da bactéria, sendo que em alguns tratamentos ocorreu até um estímulo ao crescimento (dados não mostrados). Resultados semelhantes foram obtidos por Di Piero \& Pascholati (7), onde os isolados de L. edodes não apresentaram efeito direto sobre Xanthomonas vesicatoria e os isolados de A. blazei chegaram a estimular o crescimento bacteriano in vitro. Contrariamente, Pacumbaba et al. (23), utilizando um isolado de L. edodes, obtiveram inibição do crescimento in vitro de diversas bactérias, inclusive de $R$. solanacearum. Outros compostos, como o extrato cítrico, também já foram testados in vitro visando à inibição do crescimento de bactérias, mostrando ter efeito na redução da concentração das células de $R$. solanacearum (20).

Proteção de plantas de berinjela em casa-de-vegetação

De maneira geral, o extrato aquoso do isolado $\mathrm{A} b \mathrm{bl}-28$, nas concentrações utilizadas, foi aquel eque promoveu a menor ocorrência de fol has murchas, em relação aos demais tratamentos (Figura 1). Os tratamentos com acibenzolar-S-metil e com os demais extratos aquosos 


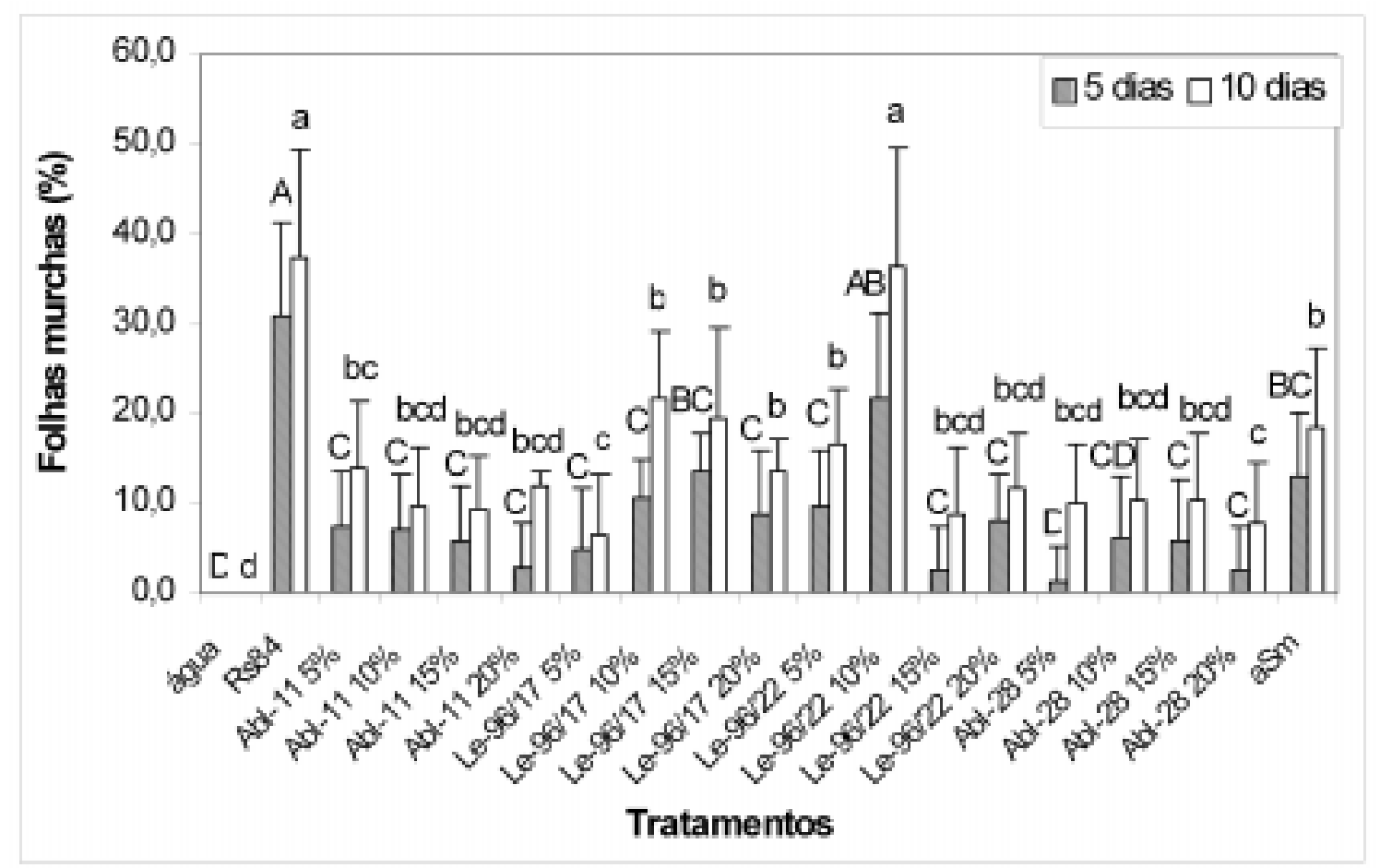

Figura 1. Efeito do acibenzolar-S-metil (aSm), dos extratos aquosos de Agaricus blazei (A bl-11 e Abl-28) e Lentinula edodes (Le-96/17 e Le-96/22), em diferentes concentrações, sobre a ocorrência de folhas murchas em plantas de berinjela, causada por Ralstonia solanacearum (Rs84). As barras representam a média \pm desvio padrão. M édias seguidas pelas mesmas letras não diferem pelo teste de Tukey a $5 \%$. As letras maiúsculas referem-se aos tratamentos avaliados aos 5 dias após a inoculação e as letras minúsculas referem-se aos tratamentos avaliados aos 10 dias após a inoculação. Os tratamentos controle são representados pela água e Rs84.

de cogumelos também proporcionaram diminuição na ocorrência de folhas murchas, quando comparados com o tratamento R s84. Quanto ao efeito dos tratamentos sobre o peso das massas fresca e seca das plantas, os extratos aquosos de A bl-11 e de Le-96/17 5\% (v/v) apresentaram resultados semel hantes àqueles obtidos para 0 tratamento controle representado pela água (dados não mostrados).

0 ef eito protetor de A bl-28 e de aSm, com base na diminuição da ocorrência de fol has murchas em berinjela, também foi observado em trabalho semelhante, realizado por Di Piero \& Pascholati (7), no patossistema tomate / Xanthomonas vesicatoria. Neste trabalho, 0 extrato aquoso deA $\mathrm{bl}-28 \mathrm{e} 0$ acibenzolar-S-metil reduziram a severidade da bacteriose. Além disso, a quantidade de inóculo bacteriano e 0 intervalo de tempo entre a aplicação dos tratamentos e a inoculação com a bactéria tiveram influência na proteção das plantas de tomate.

\section{Determinação da atividade enzimática}

Quando analisamos apenas o efeito dos tratamentos indutores sobre plantas de berinjela, sem a inoculação da bactéria, podemos obsevar que a atividade de peroxidase e quitinase do tratamento aSm diferiu significativamente do tratamento Á gua a partir do 3o dia após 0 tratamento (Figuras $2 \mathrm{~A}$ e $2 \mathrm{D}$ ). Já o tratamento A bl-28 diferiu do tratamento Á gua apenas no $12^{\circ}$ após o tratamento (Figura $2 \mathrm{~B}$ e $2 \mathrm{E}$ ). $\mathrm{Na}$ atividade de fenilalanina amônia-liase, ocorreram diferenças significativas entre o tratamento A bl-28 e o tratamento Á gua no 30, 70 e $12^{\circ}$ dias após o tratamento (Figura 3 B), sendo que para os tratamentos aSm eA bl-11 a elevação da atividade enzimática foi observada somente no $12^{\circ}$ e no $7^{\circ}$ dia após o tratamento, respectivamente (Figuras $3 \mathrm{~A}$ e 3 C). Para polifenoloxidase foi observado que sua atividade nos tratamentos aSm e A bl-28 diferiram do tratamento Á gua somente no $12^{\circ}$ dia após 0 tratamento (Figuras $3 \mathrm{D}$ e $3 \mathrm{E}$ ).
Por outro lado, quando comparamos os tratamentos com a inocul ação da bactéria, a atividade de peroxidase aumentou nas plantas tratadas com aSm e Abl-11 no $77^{\circ}$ e no $12^{\circ}$ dia após o tratamento, respectivamente, e com A bl-28 ocorreram diferenças significativas no 70 e $12^{\circ}$ dias após o tratamento, em relação ao tratamento água-R s84 (Figuras 2 A, 2 B e 2 C).

As análises bioquímicas revelaram que a quitinase, fenilalanina amônia-liase e polifenol oxidase não são bons marcadores de resistência para o patossitema em questão, visto que os tratamentos não mostraram diferenças significativas em relação ao tratamento águaRs84 (Figura 2 D , 2 E e 2 F), exceto o tratamento A bl-11, que provocou el evação na atividade de fenilalanina amônia-liase no $7^{0}$ e $12^{\circ}$ dias após o tratamento e de polifenoloxidase, no $7^{0}$ dia após o tratamento (Figura 3 C e $3 \mathrm{~F}$ ).

Essa redução na atividade de al gumas enzimas também foi verificada por Osswald et al (22) que, estudando o patossistema sorgo Colletotrichum graminicola, observaram que apesar da indução na produção de fitoalexinas ser diretamente proporcional ao aumento na dose de aSm, ocorreu uma redução na atividade das enzimas ß-1,3glucanase e quitinase.

Com relação aos mecanismos de ação envolvidos na redução da murcha bacteriana, 0 indutor acibenzolar-S-metil e 0 extrato aquoso A bl-28 de A. blazei provocaram uma elevação na atividade de peroxidase no 70 dia após o tratamento, sendo mais eficientes que o fitopatógeno em alterar a atividade da enzima. A lém disso, as plantas tratadas com A bl-28 continuaram exibindo maior atividade no 12으 dia após o tratamento. Essa maior atividade enzimática nos tratamentos aSm e A bl-28 coincidiu com a diminuição da ocorrência de folhas murchas e com 0 aumento da quantidade de proteínas (dados não mostrados) das plantas tratadas com os mesmos. As peroxidases participam de 

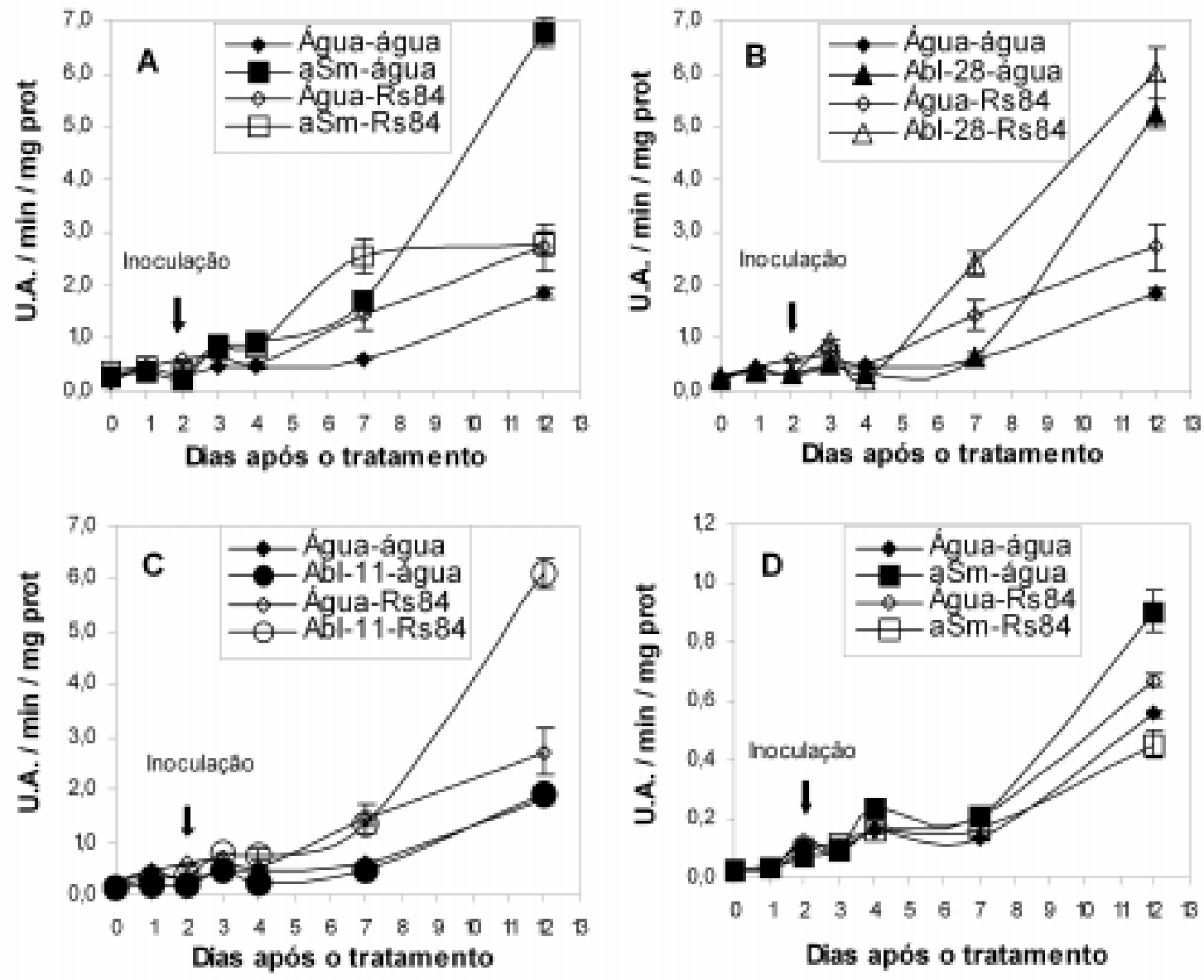

Dias após o tratamento
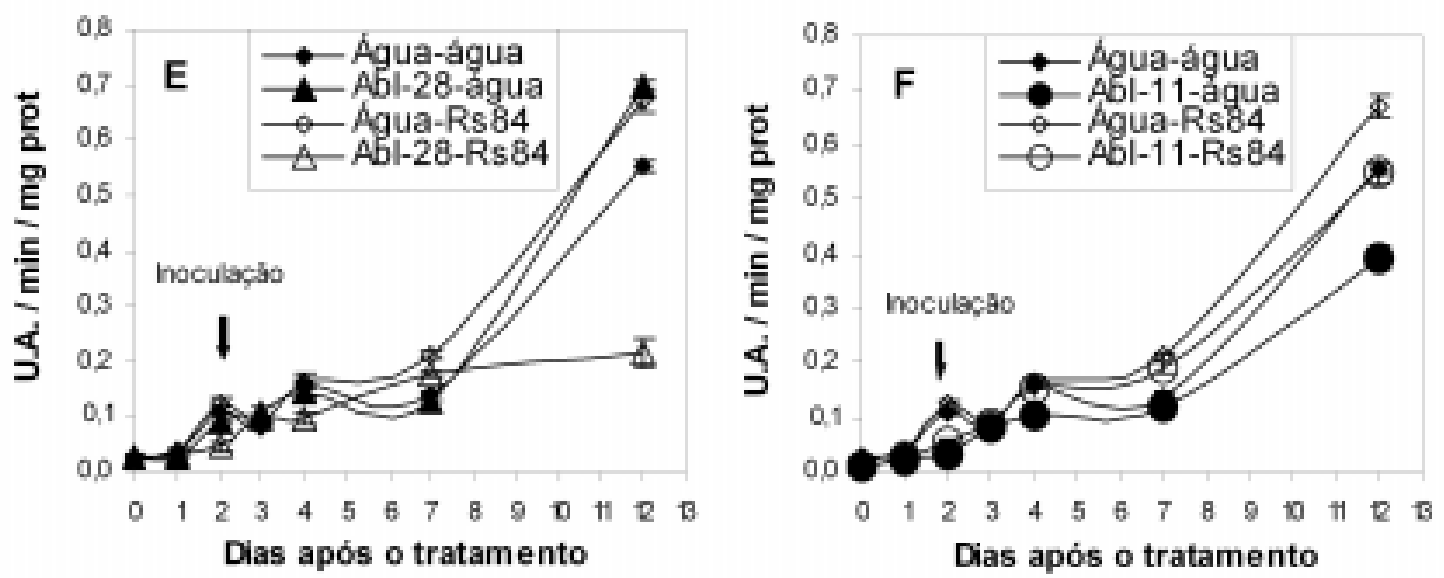

Figura 2. A tividade de peroxidase em resposta a aplicação de aSm (A) e dos extratos aquosos de Agaricus blazei A bl-28 (B) e A bl-11 (C) e atividade de quitinase após o tratamento com aSm (D), A bl-28 (E) e A bl-11 (F), nas folhas de berinjela. A seta indica o momento do tratamento com água ou da

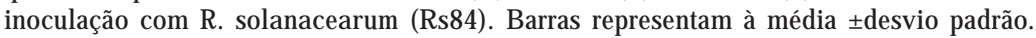

diversas reações, como ligações de polissacarídeos, oxidação do ácido indol-3-acético, ligações de monômeros, lignificação, cicatrização de ferimentos e defesa de patógenos, entre outras (3). Desse modo, os níveis de peroxidase encontrados nas fol has de berinjela tratadas com aSm e com A bl-28 (5 dias após a inoculação com a bactéria) podem ter contribuído na diminuição da ocorrência de fol has murchas. Estudando a ação de $\mathrm{aSm}$ na indução de resistência de plantas de tomate contra Clavibacter michiganensis subsp. michiganensis, Soylu et al. (27) demonstraram que o aSm reduziu a severidade da bactéria em $75 \%$ aos 7 dias após a inoculação, mantendo o mesmo nível de controle até os
14 dias após a inoculação. A lém disso, ocorreu uma maior atividade de quitinase aos 2, 3, 5 e 7 dias após a inoculação com a bactéria e uma maior atividade de peroxidase aos 5 dias após a inoculação com a bactéria nas plantas tratadas com aSm. Este aumento foi correlacionado com a expressão de resistência induzida nas plantas de tomate tratadas com aSm. Q uando este mesmo indutor foi utilizado visando o controle de Ralstonia solanacearum em três cultivares de tomateiro, ocorreu uma redução significativa do progresso da doença (1).

Por sua vez, o isolado A bl-11 de A. blazei proporcionou aumento na atividade de fenilalanina amônia-liase e polifenoloxidase, 

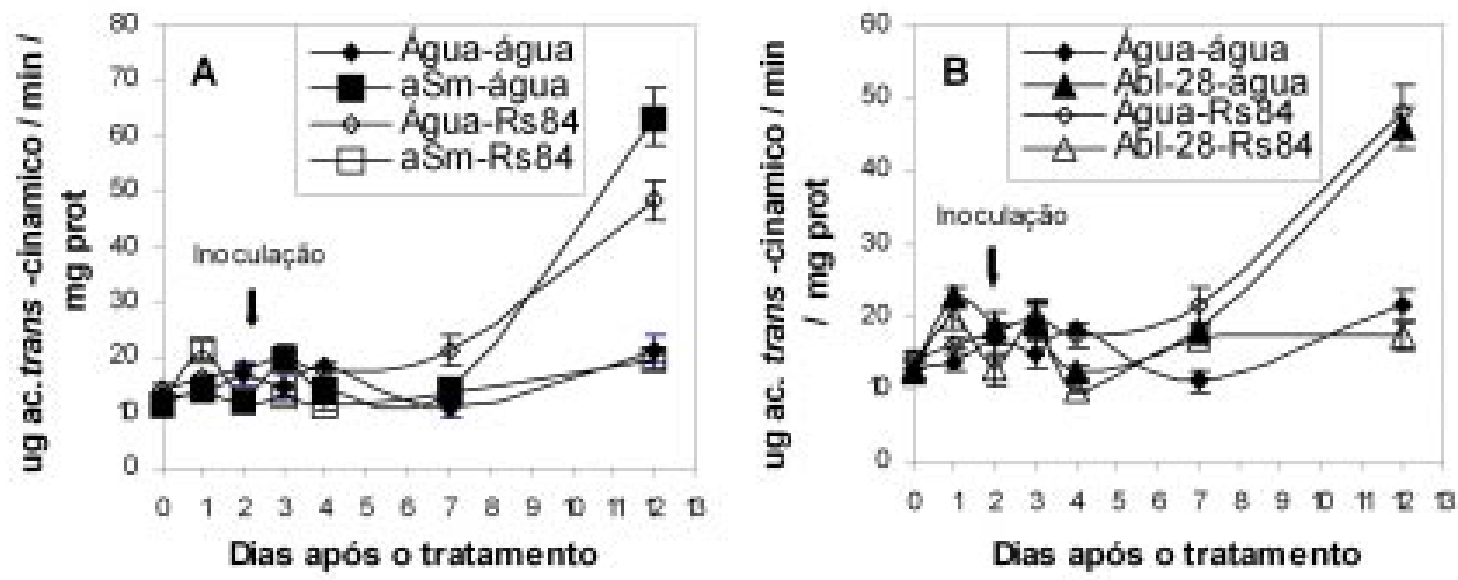

Dias após o tratamento
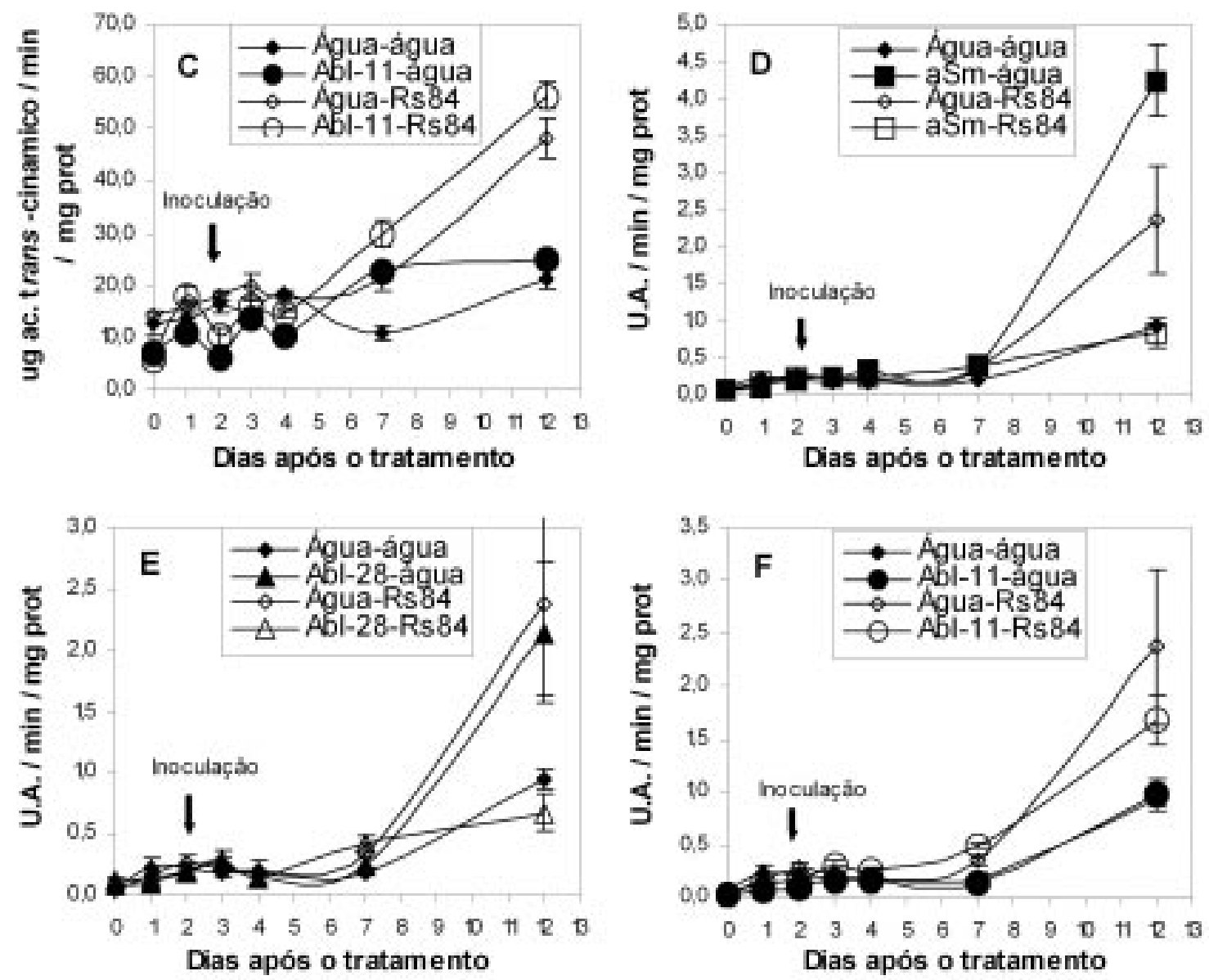

Figura 3. A tividade de fenilalanina amônia-liase em resposta a aplicação de aSm (A) e dos extratos aquosos de Agaricus blazei Abl-28 (B) e Abl-11 (C) e atividade de polifenoloxidase após o tratamento com aSm (D), A bl-28 (E) e Abl-11 (F), nas folhas de berinjela. A seta indica 0 momento do tratamento com água ou da inoculação com R. solanacearum (R s84). Barras representam à média tdesvio padrão.

demonstrando que a diminuição na ocorrência de folhas murchas pode estar relacionada com a ação deste cogumelo nas plantas de berinjela. 0 isolado Pf1 de P seudomonas fluorescens foi eficiente em reduzir a incidência de tombamento em tomate e pimentão em casa-de-vegetação e no campo, chegando também a induzir 0 aumento da atividade das enzimas fenilalanina amônia-liase, peroxidase e polifenoloxidase nas plantas de tomate e pimentão pretratadas com Pf1 e posteriormente desafiadas com Pythium a phanidermatum (26).

Di Piero (6) investigou o potencial de L. edodes e A. blazei no controle de doenças em pepino, maracujá e tomate, verificando que estes cogumel os possuem substâncias elicitoras de respostas de defesa nas plantas, podendo assim auxiliar no controle de fitopatógenos. N o presente trabalho, os extratos aquosos de basidiocarpo dos isolados A bl-11 e A bl-28 de A. blazei também demonstraram potencial para diminuir a murcha bacteriana em berinjela. A lém disso, em função da ausência de ação direta sobre o patógeno in vitro e pela ativação de mecanismos de defesa nas plantas de berinjela, sugere-se que os cogumelos atuaram induzindo resistência nas plantas de berinjela.

$$
\text { REFERÊNCIASBIBLIOGRÁFICAS }
$$


1. A raújo, J.S.P.; Gonçalves, K.S.; Oliveira, B.C.; Ribeiro, R.L.D.; Polidoro, J.C. Efeito do acibenzolar-S-metil sobre a murcha-bacteriana do tomateiro. Horticultura Brasileira, Brasília, v.23, n.1, p.5-8, 2005.

2. A raújo, J.S.P.; Robbs, C.F.; Ribeiro, R.L.D. Manejo integrado de fitobacterioses de importância econômica no Brasil. Parte 1. In: Luz, W.C.; Fernandes, J.M.C.; Prestes, A.M.; Picinini, E.C. (Eds.). Revisão anual de patologia de plantas, Passo Fundo: RAPP, 2003. v.11, p.107-131.

3. Campos, A.D.; Ferreira, A.G.; Hampe, M.M.V.; A ntunes, I.F.; Brancão, N.; Silveira, E.P.; Osório, V.A.; A ugustin, E. A tividade de peroxidase e polifenoloxidase na resistência do feijão à antracnose. Pesquisa Agropecuária Brasileira, Brasília, DF, v.39, n.7, p.637-643, 2004

4. Cavalcanti, L.S.; B runelli, K.R.; Stangarlin, J.R. A spectos moleculares da resistência induzida. In: Cavalcanti, L.S.; Di Piero, R.M.; Cia, P.; Pascholati, S.F.; Resende, M.L.V.; Romeiro, R.S. (Eds.). Indução de resistência em plantas a patógenos e insetos. Piracicaba: FEALQ, 2005. cap.4, p.81-124.

5. Cavalcanti, L.S.; Di Piero, R.M.; Cia, P.; Pascholati, S.F.; Resende, M.L.V.; Romeiro, R.S. (Eds.). Indução de resistência em plantas a patógenos e insetos. Piracicaba: Fealq, 2005. 263p.

6. Di Piero, R.M. Potencial dos cogumelos Lentinula edodes (Shiitake) e Agaricus blazei (Cogumelo-do-Sol) no controle de doenças em plantas de pepino, maracujá e tomate, e a purificação parcial de compostos biologicamente ativos. 2003. 157p. Tese (D outorado em Fitopatologia)-E scola Superior de A gricultura "L uiz de Queiroz", Universidade de São Paulo, Piracicaba.

7. Di Piero, R.M.; Pascholati, S.F. Efeitos dos cogumelos Lentinula edodes e Agaricus blazei na interação entre plantas de tomate $e$ $X$ anthomonas vesicatoria. Summa Phytopathologica, B otucatu, v.30, n.1, p.57-62, 2004

8. Duangmal, K.; A penten, R.K.O. A comparative study of polyphenoloxidases from taro (Colocasia esculenta) and potato (Solanum tuberosum var. Romano). Food Chemistry, United Kingdom, v.64, p.351-359, 1999.

9. Eira, A.F.; Kaneno, R.; Rodrigues Filho, E.; Barbisan, L.F.; Pascholati, S.F.; Di Piero, R.M.; Salvadori, D.M.F.; Lima, P.L.A.; Ribeiro, L.R. Farming technology, biochemistry characterization, and protective effects of culinary-medicinal mushrooms Agaricus brasiliensis $\mathrm{S}$. Wasser et al. and Lentinus edodes (Berk.) Singer: Five years of research in Brazil. International J ournal of Medicinal M ushrooms, New York, v.7, p.281-299, 2005.

10. Gorlach, J.; Volrath, S.; K nauf-B eiter, G.; Hengy, G.; Beckhove, U.; Kogel, K.H.; O ostendorp, M.; Staub, T.; Ward, E.; K essmann, $\mathrm{H}$.; Ryals, J. Benzothiadiazole, a novel class of inducers of systemic resistance, actives gene expression and disease resistance in wheat. The Plant Cell, B altimore, v.8, n.4, p.629-643, 1996.

11. Hammerschmidt, R; Kuae, J.; Van Loon, L.C. Inducing resistance: a summary of papers presented at the First International Symposium on Induced Resistance to Plant Diseases, Corfu, M ay 2000. European Journal of Plant Pathology, Dordrecht, v.107, n.1, p.01-06, 2001

12. Hayward, A.C. Biology and epidemiology of bacterial wilt caused by Pseudomonas solanacearum. Annual Review of Phytopathology, Palo Alto, v.29, p.65-87, 1991.

13. Ishikawa, N.K .; K asuya, M.C.M.; Vanetti, M.C.D. A ntibacterial activity of Lentinula edodes grown in liquid medium. Brazilian J ournal of Microbiology, São Paulo, v.32, p.206-210, 2001.

14. Kelman, A. The relationship of pathogenicity in Pseudomonas solanacearum to colony appearance on a tetrazolium medium. Phytopathology, Lancaster, v.44, p.693-695, 1954.

15. Kurozawa, C.; Pavan, M.A. Doenças do tomateiro. In: Kimati, H.; A morim, L.; Rezende, J.A.M.; Bergamin Filho, A.; Camargo,
L.E.A. (Eds.). M anual de fitopatologia. 4.ed. São Paulo: Ceres, 2005. v.2, p.607-626.

16. Lopes, C.A. Ecologia de Pseudomonas solanacearum. In: Taller sobre enfermidades bacterianas dela papa, Brasília, DF: EMBRAPA, CNPH, 1994. p.17-22.

17. Louws, F.J.; Wilson, M.; Campbell, H.L. Field control of bacterial spot and bacterial speck of tomato using a plant activator. Plant Disease, St. Paul, v.85, n.5, p.481-488, 2001.

18. Lusso, M.F.G.; Pascholati, S.F. A ctivity and isoenzymatic pattern of soluble peroxidases in maize tissues after mechanical injury or fungal inoculation. Summa Phytopathologica, Jaboticabal, v. 25, n. 3, p. 244-249, 1999

19. M orgado, H.S.; Lopes, C.A.; Takatsu, A. M étodos para avaliação de resistência à murcha bacteriana em berinjela. Pesquisa A gropecuária Brasileira, Brasília, DF, v.29, n.2, p.237-245, 1994.

20. M otoyama, M.N.: Schwan-Estrada, K.R.F.; Stangarlin, J.R.; Fiori, A.C.F.; Scapim, C.A. Efeito antimicrobiano de extrato cítrico sobre Ralstonia solanacearum e Xanthomonas axonopodis pv. manihotis. Acta Scientiarum A gronomy, M aringá, v.25, n.2, p.509-512, 2003.

21. Oostendorp, M.; Kunz, W.; Dietrich, B.; Staub, T. Induced disease resistance in plants by chemicals. European J ournal of Plant Pathology, Dordrecht, v.107, n.1, p.19-28, 2001.

22. Osswald, W.F.; Stangarlin, J.R.; Nicholson, R.L.; B rummer, M.; Wulff, N.A.; Di Piero, R.M.; Piccininn, E.; Di Ciero, L.; Hoto, F.V.; Pascholati, S.F.; The effect of acibenzolar-S-methyl on phytoalexin and PR-protein induction on sorghum mesocotyls and on Colletotrichum sblineolum. Summa Phytopathologica, B otucatu, v.30, n.4, p.415-420, 2004

23. Pacumbaba, R.P.; B eyl, C.A .; Pacumbaba J r., R.O. Shiitake mycelial leachate supresses growth of some bacterial species and symptoms of bacterial wilt of tomato and lima bean in vitro. Plant Disease, St. Paul, v.83, n.1, p.20-23, 1999.

24. Pascholati, S.F. Indução de resistência sistêmica: opção para 0 controle de doenças de plantas no século XXI?. Summa Phytopathologica, Botucatu, v.29, n.1, p.115-116, 2003.

25. Piccinin, E. Potencial de preparações do cogumelo comestível "shiitake" (Lentinula edodes) no controle de fitopatógenos fúngicos, bacterianos e virais em sorgo, maracujá e fumo. 2000, 162p. Tese (Doutorado em Fitopatologia)-Escola Superior de A gricultura" Luiz de Queiroz", Universidade de SãoPaulo, Piracicaba.

26. Ramamoorthy, V.; Raguchander, T.; Samiyappan, R. Enhancing resistance of tomato and hot pepper to Pythium diseases by seed treatment with fluorescent pseudomonads. European J ournal of Plant Pathology, Dordrecht, v.108, p.429-441, 2002.

27. Soylu, S.; Baysal, O.; Soylu, E.M. Induction of disease resistance by the plant activator, acibenzolar-S-methyl (ASM), against bacterial canker (Clavibacter michiganensis subsp. michiganensis) in tomato seedlings. Plant Science, A msterdam, v.165, p.1069$1075,2003$.

28. Takatsu, A.; Lopes, C.A. M urcha-bacteriana em hortaliças: avanços científicos e perspectivas de controle. Horticultura Brasileira, B rasília, DF, v.15, p.170-177, 1997.

29. Umesha, S. Phenylalanine ammonia lyase activity in tomato seedlings and its relationship to bacterial canker disease resistance. Phytoparasitica, Israel, v.34, n.1, p.68-71, 2006.

30. Wakimoto, S.; Utatsu, K.; M atsuo, N.; Hayashi, N. M ultiplication of Pseudomonas solanacearum in pure water. Annals of Phytopathology Society of J apan, Tokyo, v.48, p.620-627, 1982.

31. Wirth, S.J.; Wolf, G.A. Dye-labelled substrates for the assay and detection of chitinase and Iysozyme activity. J ournal of $\mathrm{Mi}$ crobiological Methods, A msterdam, v.12, n.3-4, p.197-205, 1990. 